\title{
Gender Equity in Academic Medicine: Why Should We Care?
}

Sonia S. Anand MD, PhD, FRCPc, Anita I. Anand, BA, BA, LLB, LLM

\section{About the Author \\ Sonia S. Anand is with the Department of Medicine, McMaster University, Hamilton, ON. Anita I. Anand is with the Faculty of Law, University of Toronto, Toronto, ON. \\ Address for Correspondence: anands@mcmaster.ca \\ Submitted: May 24, 2018. Accepted: October 10, 2018. Published: February X, 2019. DOI: 10.22374/cjgim. v14i1.289}

\begin{abstract}
Gender disparity exists generally in academia and specifically in research and education among academic medical specialists. Reasons for this disparity include overt and unconscious biases that result in women being offered fewer opportunities to lead, receiving less compensation, being excluded from networking channels in which academic positions are discussed, and facing bias in research, including in the peer review grant process. The recent spotlight on these disparities in other sectors leads us to probe the causes and consequences of gender disparity in academic medicine and to advocate for structural changes to ensure gender equity in academia.

Resume

La disparité entre les sexes existe généralement dans le monde universitaire, et plus particulièrement dans la recherche et la formation des spécialistes médicaux en médecine. Parmi les raisons de cette disparité, citons les préjugés évidents et inconscients qui ont pour résultat moins de possibilités de diriger offertes aux femmes; elles reçoivent une plus faible rémunération, sont exclues des réseaux de discussion dans lesquels les postes universitaires sont discutés et font face à des biais dans la recherche, y compris dans le processus de subvention par les pairs. La récente mise en lumière de ces disparités dans d'autres secteurs nous amène à rechercher les causes et les conséquences de la disparité entre les sexes en médecine universitaire et à plaider en faveur des changements structurels pour assurer l'équité entre les sexes dans les universités.
\end{abstract}

Keywords: gender, academic, medicine, bias

Gender equality in the areas of health, education, business leadership, law, and political leadership remains a work in progress. ${ }^{1}$ According to the World Economic Forum Report on Gender, at current rates of change, it will take 217 years for women to reach gender parity (defined as the female-to-male equality for a given indicator), with the greatest increases required in the areas of economic and political leadership. Canada is ranked 16th in gender parity among countries of the world, with Iceland being the best country and Yemen being the worst. ${ }^{1}$ In Canada, gender parity has been achieved to some extent in certain areas of health and education but not in business and political leadership positions. ${ }^{1}$

Specifically, gender parity among medical school graduates in Canada was attained in the mid-eighties, ${ }^{2}$ and now more women than men graduate from medical schools in Canada. ${ }^{2}$ The 2015-16 Canadian Post-MD Education Registry (CAPER) Census reveals that of the almost 14,000 physicians in Canadian postgraduate medical training, $53.4 \%$ are female and $46.6 \%$ are male. ${ }^{3}$ Entry into specialities such as internal medicine appears about equal, with $54 \%$ women entering postgraduate training 
programs in medical specialities. ${ }^{2}$ The percentage of women entering academic medical specialist practices at the lecturer or assistant professor level is also approximately $50 \% .{ }^{4}$

However, among academic medical specialists in Canada and the United States, in the decade after taking up a faculty position, women are less likely to achieve full professor status, and more likely to leave academic medicine. This phenomenon can be referred to as a "leaky pipeline" since women do not follow the hierarchical path or "pipeline" towards senior positions. ${ }^{4}$ They leave or experience stagnation by rank in internal medicine and its related specialities over time, with only $25 \%$ of full professors being women, and only $15 \%$ of leadership positions such as dean are held by women. ${ }^{4}$

Statistics such as these encourage us to examine more deeply the factors that underlie the leaky pipeline. Although it is commonly believed that women choose to leave academic medicine, emerging evidence suggests that women face both overt and unconscious biases, and may in effect be pushed out of an academic career in medicine. Overt biases that drive women from the pursuit of an academic career can include workplace bullying and sexual harassment. In the United States, it is estimated that amongst the career development (K) award holders, $30 \%$ of women have personally experienced sexual harassment, ${ }^{5}$ and it is likely similar in Canada. ${ }^{6}$ Overt biases such as these can have long-lasting effects on the career paths of women in medicine, especially if they become disillusioned by systemic biases and thus do not seek career advancement. They may also suffer from low self-esteem ${ }^{5}$ and/or imposter syndrome. ${ }^{7}$

In the past year, the \#MeToo movement has increased society's awareness of workplace biases, which stifle career advancement in all domains of society including in business, entertainment, academia, and hospital systems. ${ }^{8}$ At the same time, students graduating from medical school have a greater awareness that such behaviours are unacceptable, and they seek to inform their leaders about it. ${ }^{9}$ Heads of both hospitals and universities are thus reviewing their policies and procedures so that complaints of sexual harassment and workplace bullying can be effectively addressed. ${ }^{10}$

The second type of bias that women face is known as "unconscious" or "implicit" bias. ${ }^{7}$ That is, women may not be encouraged to apply for promotion or leadership positions. They may not seem like a "natural fit" given that they are often not privy to the same informal networking opportunities as their male colleagues. Implicit biases can also creep into play when selection committees are comprised of only or mostly men, with little female or LGBTQ representation. Subtle biases can result in lower assessment ratings or subjective decisions by the committees about women's academic record and their ability to take on work given their home responsibilities.

Finally, research shows us that, even when women have equal or greater qualifications than male colleagues, they can suffer from the "imposter syndrome," feeling underqualified or incapable to apply for or have the confidence to take on leadership positions. ${ }^{7}$ A recent computer simulation model of the business sector created at Rice University demonstrates that subtle differences in performance ratings (which may reflect gender bias) over time lead to leadership positions being held by $65 \%$ men and only $35 \%$ of women at the most senior level, even if they entered the organization at equal rates. ${ }^{11}$

Research bias in peer grant review also exists, with women scientists being less likely than male scientists to be funded and published. ${ }^{12}$ In keeping with these biases, there may be greater concerns about the ability of successful women scientists to lead multiple funded projects, resulting in lower application scores and lower funding success. A recent analysis of all grant applications submitted to the Canadian Institutes of Health Research (CIHR) between 2012 and 2014 by Tamblyn et al. showed that women's applications were more likely to be scored lower than men's to a degree that could impact grant funding success rates after accounting for many potential modifying factors (i.e., past funding success, scientific productivity, reviewer characteristics, etc.). ${ }^{13}$ Given women's lower success rates in CIHR funding, a vicious cycle can result, with women making fewer applications, receiving rejections, and therefore having fewer research successes. Grant reviewer training - including unconscious bias training - would be useful to alter this trend.

But the bias is not simply implicit. A recent Canadian Medical Association analysis demonstrates that women earn less than men in medical professions. As billings are fee-for-service, this differential may indeed represent choices by women to work in different domains which are less lucrative, or to reduce working time in order to devote attention to child-rearing and household management. However, there may well be underlying issues at play, including men receiving greater access to more lucrative billing opportunities, such as in diagnostic testing or choice clinical billing domains.

Within academic centres, there are multiple sources of salary from public institutions (i.e., hospital or university stipends and research funds), and these sources are used to support academics in their educational and research programs. Apart from billings, additional salary sources can be negotiated with the hospital or university leadership. Because women attain fewer leadership positions, they are less likely to be in a position to negotiate for increases to base salaries and stipends. 
How can we mitigate and overcome unconscious biases? In the past, the onus has been placed on women to change themselves to suit the work environment by taking leadership courses, joining women's networking groups, and seeking out more mentorship. ${ }^{7}$ However, research from the business sector suggests the most effective way to mitigate unconscious bias is through structural change. ${ }^{7,14}$ Such changes could include: committing to unconscious bias training for all faculty members; ensuring equal representation of men and women on leadership selection committees; encouraging more women towards applying for leadership positions; and, setting gender or diversity targets for leadership positions. ${ }^{7}$

Those at the highest levels of leadership (i.e., deans or chairs) should lead the effort to make structural changes rather than leaving it to women, or groups of women, in subordinate positions to advocate for these changes. ${ }^{15}$ Programs such as the Athena Scientific Women's Academic Network (SWAN), established in 2005 in the United Kingdom, are designed to encourage and recognize the commitment of academic institutions to advance the careers of women in science, technology, engineering, and mathematics (STEM) in higher education and research. ${ }^{15}$ (Table 1) Such frameworks have a significant role to play in eliminating the biases that negatively affect women in academia, but much of the work must begin from within the institutions themselves.

A recent study conducted at University of Toronto's department of medicine demonstrated that stereotypes about women were reinforced in the department as a result of women's exclusion from certain specialities and informal networking (for instance, when meetings were held at times of day which conflicted with child care responsibilities). The same study found that unprofessional behaviour (including sexist remarks) were perceived to impact gender diversity in workplace culture in academic medicine. ${ }^{16}$ Participants proposed several interventions to counteract the gender gap, including changes in recruitment, hiring and promotion practices, improvements to work environments, mentorship, and ongoing monitoring and examination of the gender gap. Table 1. Specific Action for Academic Medical Programs

1. Recognize unconscious bias and provide unconscious bias training for faculty and staff.

2. Adopt similar training programs across universities as has been put forward by Athena SWAN in the United Kingdom.

3. Recognize gender pay inequity in academic medicine and make base salaries and stipends transparent by rank and academic stream.

4. Ensure gender equity in committee composition and distribution of leadership roles, research chairs other important positions.

\section{Summary}

Women in academic medicine face overt and unconscious biases which in turn contribute to a leaky pipeline and differential success in academic research and educational advancement. We advocate for structural changes in Canadian medical schools and medical departments in order to promote a merit-based, unbiased path to equality for women in academic medicine. Such change will occur only by recognizing the persistence of gender bias and working to ensure that the leadership of these institutions reflects the demographic constituencies that they serve. We believe that similar analyses are warranted in other disciplines and sectors.

\section{References}

1. World Economic Forum. The Global Gender Gap Report 20172017.

2. The Expert Panel on Women in University Research. Strengthening Canada's Research Capacity: The Gender Dimension. Ottawa, Canada; 2012.

3. The Association of Faculties of Medicine of Canada. Annual Census of PostM.D. Trainees 2015-2016. Ottawa, Canada: Canadian Post-MD Education Registry; 2016.

4. The Association of American Medical Colleges. Diversity in the Physician Workforce: Facts \& Figures 2014. Washington, DC: Association of American Medical Colleges; 2014.

5. Jagsi R, Griffith KA, Jones R, et al. Sexual harassment and discrimination experiences of academic medical faculty. JAMA 2016;315(19):2120-1.

6. van Wylick R, Kwon J. Sexual harassment at medical schools. CMAJ : Canadian Medical Association journal = journal de l'Association medicale canadienne 1993;148(7):1120.

7. Bohnet I. What works: gender equality by design: The Belknap Press of Harvard University Press; 2016.

8. Freischlag JA, Faria P. It is time for women (and men) to be brave: a consequence of the \#metoo movement. JAMA 2018.

9. Antman K. Building on \#metoo to enhance the learning environment for US medical schools JAMA 2018.

10. Leeder J. Investigator finds culture of disrespect, harassment at MUN medical school. In: The Globe and Mail. Philip Crawley, Toronto, Canada. 2018. https://www.theglobeandmail.com/canada/article-investigator-finds-cultureof-disrespect-harassment-at-mun-medical/. Accessed August 7, 2018.

11. Hill P. Gender Bias and its Cumulative Effect On Careers and Organizations. RICE University. http://doesgenderbiasmatter.com/. Accessed May 7, 2018.

12. Magua W, Zhu X, Bhattacharya A, et al. Are female applicants disadvantaged in national institutes of health peer review? combining algorithmic text mining and qualitative methods to detect evaluative differences in r01 reviewers' critiques. J Women's Health 2017;26(5):560-70.

13. Tamblyn R, Girard N, Qian CJ, et al. Assessment of potential bias in research grant peer review in Canada. CMAJ : Canadian Medical Association journal = journal de l'Association medicale canadienne. 2018;190(16):E489-E99.

14. Isaac C, Lee B, Carnes M. Interventions that affect gender bias in hiring: a systematic review. Acad Med 2009;84(10):1440-6.

15. Equality Challenge Unit. History of Athena SWAN (pre May 2015). England and Wales. https://www.ecu.ac.uk/equality-charters/athena-swan/aboutathena-swan/history-of-athena-swan/. Accessed August 1, 2016.

16. Pattani R, Marquez C, Dinyarian C, et al. The perceived organizational impact of the gender gap across a Canadian department of medicine and proposed strategies to combat it: a qualitative study. BMC Med 2018;16(1):48. 